\title{
Characterisation and phylogenetic analysis of the VP7 proteins of serotype G6 and G8 human rotaviruses
}

\author{
M. A. COONEY, R. J. GORRELL and E. A. PALOMBO†
}

Department of Gastroenterology and Clinical Nutrition, Royal Children's Hospital, Flemington Road, Parkville, Victoria 3052 and $\dagger$ School of Engineering and Science, Swinburne University of Technology, PO Box 218 Hawthorn, Victoria 3122, Australia

\begin{abstract}
Serotype G6 and G8 rotaviruses are rarely found in man and may have originated in animals. Human serotype G6 and G8 rotaviruses, isolated from hospitalised children at various locations in Australia, were characterised. Deduced amino acid sequences of the major neutralising antigen, V7, showed significant identity to the cognate proteins of prototype human and bovine G6 and G8 viruses, respectively, and the strains reacted with G6 and G8 serotype-specific neutralising monoclonal antibodies, respectively, in an enzyme immunoassay. The VP4 type was determined as P[14] for all strains tested. Phylogenetic analysis of these and other human and bovine VP7 sequences suggested that a single inter-species transmission event, possibly from cattle, may have led to the emergence of G6 viruses in man. In contrast, the exchange of genes between human and bovine G8 viruses may have occurred on more than one occasion, or these genes may have originated in a different host.
\end{abstract}

\section{Introduction}

Group A rotaviruses, the major agents of severe gastroenteritis in infants and young children worldwide, are classified into 14 serotypes based on the antigenic specificity of the major outer capsid glycoprotein and neutralisation antigen, VP7 [1]. Four of these serotypes, or G-types, (G1, 2, 3 and 4) are commonly found as a cause of severe gastro-enteritis in children [2]. Hence, protection against these is seen as a primary goal of effective human rotavirus vaccines. However, the increased number of reports of clinical isolates exhibiting diverse G-type specificities, such as G5 [3], G8 [4] and G9 [5], raises the concern that new G-types may be emerging as human pathogens. Given that some of these serotypes are more commonly found in animals, the possibility of inter-species transmission of rotavirus strains has been suggested. This has implications for vaccine strategies based on the use of re-assortant human-animal strains.

Serotype G6 and G8 rotaviruses have been reported as pathogens of various animal species. However, the recent description of these serotypes among human

Received 25 September 2000; accepted 16 Oct. 2000.

Corresponding author: Dr E. A. Palombo

(e-mail: epalombo@swin.edu.au). clinical isolates suggests that inter-species transmission has led to their emergence in man. This report describes human G6 and G8 rotavirus isolates collected from children admitted to hospital with acute gastroenteritis in various Australian locations (Melbourne, Brisbane and Adelaide). The genetic and antigenic characteristics of these isolates were determined, and phylogenetic analysis of the VP7 proteins of several human and bovine strains was performed.

\section{Materials and methods}

Source of viruses

Routine serotyping of rotavirus clinical isolates at the Royal Children's Hospital, Parkville, Victoria, identified three isolates, collected during 1996 and 1997, which were not reactive with neutralising monoclonal antibodies (NMAbs) specific for G-types 1-4 in enzyme immunoassay (EIA). These isolates were all classified as VP6 subgroup I and exhibited a 'long' electropherotype (i.e., migration pattern of genomic double-stranded RNA segments in polyacrylamide gels). The combination of subgroup I and a 'long' electropherotype is usually found in animal strains [6], suggesting that these human strains may have been derived from animal rotaviruses. Two of the isolates were adapted to growth in MA104 cells in the presence 
of porcine trypsin $1 \mu \mathrm{g} / \mathrm{ml}$. It was not possible to adapt the other isolate. A further isolate, collected in Melbourne in 1981, was also investigated, as serum antibody studies indicated that the patient had been infected by an atypical (non-G1-4) rotavirus. This virus was not adapted because of insufficient faecal material. Standard rotavirus strains used in this study and their G-type designations were as follows: RV4 (G1), Wa (G1), M37 (G1), RV5 (G2), S2 (G2), 1076 (G2), RV3 (G3), P (G3), ST3 (G4), PA169 (G6), UK (G6), MG6 (G6), B37 (G8), HAL1166 (G8), DG8 (G8) and F45 (G9). The viruses were grown in MA104 cells and partially purified by fluorocarbon extraction and ultracentrifugation.

\section{Extraction of double-stranded $R N A$, reverse transcriptase-PCR and VP7 sequence analysis}

Double-stranded RNA was isolated from faecal homogenates $10 \% \mathrm{w} / \mathrm{v}$ or from tissue-culture supernate by phenol-chloroform extraction, purified by adsorption to hydroxyapatite and eluted in potassium phosphate buffer [7]. To determine the G-type of the untypable strains, cDNA of the VP7 gene was derived by reverse transcriptase (RT)-PCR with gene-specific primers [8]. The cDNA was cloned into the vector pT7-Blue (Novagen) and the nucleotide sequences of the VP7 genes were determined with the fmol DNA Sequencing System (Promega, USA) and gene-specific primers. Deduced amino acid sequences of VP7 were determined and compared to standard strains representing each of the 14 known G-types. Sequences have been deposited in the GenBank database and assigned the accession numbers AF207060-AF207063.

\section{Determination of VP7 serotype}

G-serotyping of tissue-culture-adapted strains with the G6-specific NMAb, N2/A7 (at a dilution of 1 in 20 000) and the G8-specific NMAb, B37:1 (1 in 32000) was performed by EIA as described previously [9]. Briefly, microtitration plates were coated with homologous rabbit polyclonal antibody or pre-immune immunoglobulins followed by incubation with tissue-culture supernate. NMAbs were added at the appropriate dilutions and detected with anti-mouse immunoglobulins conjugated to horseradish peroxidase (AMRAD, Australia). The substrate used to detect bound immunoglobulinenzyme complexes was 3,3',5,5'-tetramethylbenzidine and the absorbance was measured at $450 \mathrm{~nm}$.

\section{Determination of VP4 type}

The VP4 type (P-type) was determined with a digoxigenin (DIG)-11-dUTP-labelled P[14]-specific probe in Northern hybridisation as described previously [10]. Pre-hybridisation and hybridisation were done under stringent conditions (formamide $50 \%, 5 \times \mathrm{SSC}$, $56^{\circ} \mathrm{C}$ ). After post-hybridisation washes, bound probe was detected with anti-DIG antibody conjugated to alkaline phosphatase (Roche Biochemicals, Germany) and the chemiluminescent substrate CDP-Star (Roche Biochemicals).

\section{Phylogenetic analysis}

Deduced VP7 sequences were aligned by using ECLUSTALW (through the Australian Genomic Information Service, University of Sydney) and phylogenetic analysis was performed with the MEGA analytical package [11]. Genetic distances (p-distances) were calculated, replicate data sets (500) were generated by bootstrap re-sampling and a phylogenetic tree was constructed by the neighbour-joining method.

\section{Results}

\section{VP7 sequence analysis and determination of $G$ - type}

The four isolates investigated were found to be nonreactive to NMAbs specific for the common human VP7 types G1-G4 in EIA. To determine their G-type, the sequences of the VP7 genes and the deduced VP7 amino acid sequences were determined. All strains contained VP7 genes of $1062 \mathrm{bp}$ and encoded a polypeptide of 326 amino acids. Comparisons of the deduced amino acid sequences with those of prototype rotavirus strains representing the 14 known G-types indicated that two isolates exhibited $97-98 \%$ identity to the standard G6 strain, PA169, whereas the other isolates were $98 \%$ identical to the standard G8 strain, HAL1166. As the VP7 of strains of the same G-type usually exhibits $>91 \%$ amino acid identity [1], the isolates were classified into either G6 or G8 and were thus designated MG6.01, aG6.01, BG8.01 and mG8.01, with the first letter indicating the city of origin (i.e., $\mathrm{M}$ or $\mathrm{m}=$ Melbourne, $\mathrm{B}=$ Brisbane and $\mathrm{a}=$ Adelaide. The upper case letters indicate isolates that were adapted to cell culture).

The sequences of the VP7 neutralisation epitope regions of the strains were compared to those of standard G6 and G8 viruses, as these regions are known to be conserved within G-types but divergent between G-types [1]. All strains showed high levels of sequence identity to viruses belonging to the same Gtype as predicted from overall VP7 sequence analysis, especially the G8 viruses (Fig. 1). However, the G6 viruses exhibited a greater level of variation, which was particularly evident between human and bovine strains. To confirm the genetic classification of the G6 and G8 strains, EIA was performed with the tissue-cultureadapted strains and the G6-specific NMAb, N2/A7 and the G8-specific NMAb, B37:1 (Table 1). This analysis confirmed that MG6.01 and BG8.01 exhibited the antigenic characteristics of serotype G6 and G8 rotaviruses, respectively. 


\begin{tabular}{|c|c|c|c|}
\hline Serotype & G6 & & \\
\hline & $\begin{array}{ll}87 & 101\end{array}$ & $142 \quad 152$ & $208 \quad 221$ \\
\hline$M G 6.01$ & VEASNEIADTEWKNT & MKYDSTLELDM & LITDPNTEETVATT \\
\hline$a G 6.01$ & $\ldots \ldots \ldots \ldots \ldots$ & $\ldots \ldots \ldots \ldots$ & $\ldots \ldots \ldots \ldots$ \\
\hline MG 6 & $\ldots \ldots \ldots \ldots \ldots$ & $\ldots \ldots \ldots \ldots$ &. T........ \\
\hline PA151 & T........... & $\ldots N \ldots \ldots$ & .T.......A \\
\hline PA169 & $\ldots \ldots \ldots \ldots$ & $\ldots \ldots \ldots \ldots$ &. $\mathrm{T} \ldots \ldots \ldots$ \\
\hline UK & $\ldots \ldots \ldots \ldots$ & $\ldots \ldots Q \ldots$ & $\ldots$ N.D...... \\
\hline NCDV & $\ldots \ldots \ldots \ldots$. . & $\ldots \ldots Q \ldots$ & $\ldots N . D \ldots . . M$ \\
\hline B 60 & $\ldots \ldots \ldots{ }_{1}$ & $\ldots \ldots Q \ldots$ & ..N.D...... \\
\hline IND & $\ldots \ldots \ldots{ }_{1}$ & $\ldots \ldots Q \ldots$ & $\ldots$. . . ...... \\
\hline B 641 & $\ldots$.... & $\ldots \ldots \mathrm{QK} \ldots$ & $\ldots$ N.D....... \\
\hline VRMI & $\ldots \ldots M \ldots$.... & $\ldots \ldots Q \ldots$ & $\ldots$. N.D.....P \\
\hline BRU033 & $\ldots \ldots \ldots \ldots D A$ & $\ldots \ldots Q \ldots$ & $\ldots N . D \ldots . . M M$ \\
\hline MC2 7 & I $\ldots \ldots \ldots$ & $\ldots . . Q \ldots$ & ST.N.D.....Q \\
\hline
\end{tabular}

\section{Serotype $\mathbf{6 8}$}

\begin{tabular}{|c|c|}
\hline & 87 \\
\hline$B G 8.01$ & VEAETEIADSSWKD \\
\hline$m G 8.01$ & $\cdots \cdots \cdots \cdots \cdots$ \\
\hline$D G 8$ & $\ldots \ldots \ldots \ldots$ \\
\hline HAL 1166 & $\ldots \ldots \ldots$ \\
\hline B37 & $\ldots \ldots \ldots \ldots$ \\
\hline $69 M$ & $\ldots \ldots \ldots \ldots$ \\
\hline EGY1850 & $A \ldots \ldots \ldots$ \\
\hline EGY2295 & $T \ldots \ldots . . .$. \\
\hline GR570 & A........... \\
\hline QEH14262 & 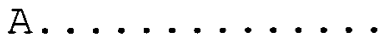 \\
\hline UP30 & 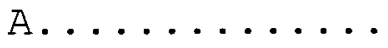 \\
\hline HMG89 & 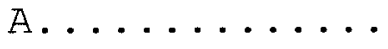 \\
\hline MP409 & 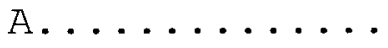 \\
\hline A 5 & $\mathrm{~T} \ldots \ldots . . .$. \\
\hline 67 & \\
\hline
\end{tabular}

$142 \quad 152$

MKYNANSELDM

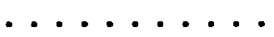

$\ldots \ldots \ldots$

$\ldots \ldots \ldots$

$\ldots \ldots \ldots$

$\ldots \ldots \ldots$

$\ldots \ldots \ldots$

$\ldots \ldots \ldots$

$\ldots \ldots \ldots$

$\ldots \ldots \ldots$

$\ldots \ldots \ldots$

$\ldots \ldots \mathrm{D} \ldots \ldots$

$\ldots \ldots \ldots$

$\ldots \ldots$.........

$\ldots \ldots \ldots$
208

221

LTTDTTTEEEVATA

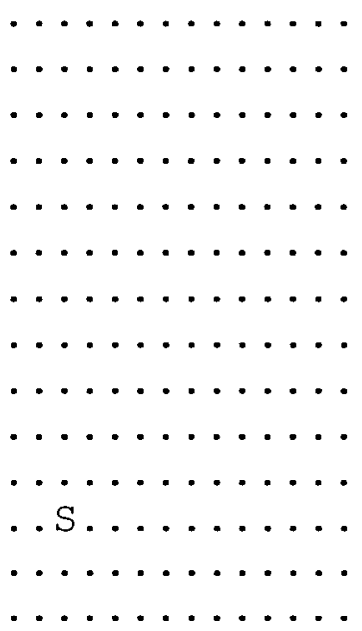

Fig. 1. Alignments of deduced amino acid sequences of VP7 antigenic regions A (amino acids 87-101), B (aa 142152) and C (aa 208-221) of serotype G6 and G8 human and bovine rotaviruses. Dots indicate identity to MG6.01, for G6 strains, and BG8.01, for G8 strains. Human strains are in italics. Sequences were obtained from the GenBank database - accession numbers AF034852 (DG8), AF104102 (EGY1850), AF104104 (EGY2295), AF141918 (MP409), AF143688 (GR570), AF143689 (QEH14262), AF143690 (UP30), AF162435 (MC27), D13395 (A5), J04334 (B37), L20880 (PA169), L20881 (PA151), L20883 (678), L20882 (HAL1166), M12394 (NCDV), M63266 (B641), M64680 (B60), U15000 (IND), U22011 (MG6), U50332 (VRMI), U62154 (BRU033), X00896 (UK), X98918 (HMG89) - Green et al. [12] (69M) or determined in this study - accession numbers AF207060 (BG8.01), AF207061 (mG8.01), AF207062 (MG6.01), AF207063 (aG6.01).

\section{Determination of P-type}

Human G6 and G8 strains have been found to be associated with uncommon outer capsid neutralisation protein VP4 specificities [13]. The VP4 genotype (Pgenotype) of the adapted strains was determined by Northern hybridisation and these strains were found to belong to genotype $\mathrm{P}[14]$ (data not shown). This is in common with previously described Australian G6 [10] and G8 [14] strains. Partial sequencing of the VP4 gene of mG8.01 also suggested that this strain belonged to $\mathrm{P}[14]$.

\section{Phylogenetic analysis of VP7 proteins}

Given that G6 and G8 rotaviruses have been associated with cattle $[15,16]$ and that a number of bovine G6 and G8 VP7 sequences were available in sequence databases, the study examined the genetic relatedness of human and bovine G6 and G8 VP7 proteins. The sequences of various human and bovine VP7 proteins (obtained from the GenBank database) and those determined in this study were analysed by MEGA analysis. Fig. 2a shows that, with the exception of the human strain PA151 and the bovine 
Table 1. Reactivity of rotavirus strains with serotype G6-specific NMAb N2/A7 and serotype G8-specific NMAb B37:1 in EIA

\begin{tabular}{lccc}
\hline & & \multicolumn{2}{c}{$\mathrm{P} / \mathrm{N}$ value* with NMAb } \\
\cline { 3 - 4 } Strain & G-serotype & $\mathrm{N} 2 / \mathrm{A} 7$ & $\mathrm{~B} 37: 1$ \\
\hline RV4 & 1 & 0.87 & 1.65 \\
Wa & 1 & 0.96 & 0.99 \\
M37 & 1 & 1.09 & 0.51 \\
RV5 & 2 & 1.00 & 1.37 \\
S2 & 2 & 1.00 & 1.11 \\
1076 & 2 & 1.09 & 1.17 \\
RV3 & 3 & 1.01 & 1.16 \\
P & 3 & 1.06 & 1.82 \\
ST3 & 4 & 0.99 & 1.56 \\
PA169 & 6 & $\mathbf{3 . 5 0}$ & 0.97 \\
UK & 6 & $\mathbf{1 7 . 5 9}$ & 1.00 \\
MG6 & 6 & $\mathbf{7 . 5 8}$ & 0.96 \\
B37 & 8 & 0.89 & $\mathbf{1 7 . 7 3}$ \\
HAL1166 & 8 & 0.97 & $\mathbf{1 5 . 2 3}$ \\
DG8 & 8 & 1.02 & $\mathbf{3 2 . 7 5}$ \\
F45 & 9 & 0.96 & 1.31 \\
MG6.01 & $?$ & $\mathbf{1 5 . 7 0}$ & 1.20 \\
BG8.01 & $?$ & 1.04 & $\mathbf{3 0 . 1 6}$ \\
\hline F & & &
\end{tabular}

*A virus was considered to have a positive reactivity if its $\mathrm{A}_{450}$ with a given NMAb, with homologous polyclonal antibody as the coating antibody, ( $\mathrm{P}$ value) was at least twice the $\mathrm{A}_{450}$ value obtained with pre-immune immunoglobulins ( $\mathrm{N}$ value), i.e., a $\mathrm{P} / \mathrm{N}$ value $\geqslant 2.0$. Positive values are in bold type.

strain MC27, there was a clear separation of G6 bovine and human VP7 sequences, such that sequences from each species were distinct from those of the other. The general species-specific clustering was not related to the geographical origin of strains. For example, human strains were isolated in Italy (PA169) and Australia, whereas bovine strains were from diverse locations such as India, USA, UK and Australia. PA151 (also isolated in Italy) and MC27 were found on a separate branch located between the other human and bovine sequences. Thus, this branch may represent the point at which an inter-species transmission event occurred between cattle and man.

In contrast to the G6 viruses, no clear distinction between the VP7 of human and bovine G8 viruses was evident, with the two bovine strains located within different branches containing human sequences (Fig. 2b). However, some evidence of geographical clustering of human strains was evident with strains from Australia (DG8, BG8.01 and mG8.01) and Indonesia (B37 and 69M) found in neighbouring branches. Although the two Egyptian strains (EGY1850 and EGY2295) were distantly related, other strains from Africa (i.e., GR570 and UP30 from South Africa and HMG89 from Nigeria) clustered together. This may indicate independent origins for geographically related viruses. Other human G8 strains were isolated in Finland (HAL1166), the UK (QEH14262) and India (MP409).

\section{Discussion}

Genetic and antigenic analysis of atypical human rotavirus strains indicated that these viruses could be classified as either serotype G6 or G8. Where the Ptype was determined, the strains were found to belong to $\mathrm{P}[14]$. Phylogenetic analysis of human and bovine strains indicated that, if the human G6 and G8 viruses derived their VP7 genes from bovine strains (or vice versa), the transmission events occurred by different mechanisms. For the G6 viruses the inter-species transmission may have occurred as a single event between an MC27-like virus and a PA151-like virus. Apart from this relationship, the VP7 proteins from each species were generally phylogenetically distinct. For the human G6 viruses whose P-type is known, those with $\mathrm{P}[14]$ specificity (PA169, MG6 and MG6.01) were distinct from PA151, which exhibits $\mathrm{P}[9]$ specificity. This suggests that the human viruses have diverged into distinct lineages which correlate with P-type specificity. Hence, the introduction of G6 VP7 into the human virus population may not have been a recent phenomenon.

In contrast, the exchange of serotype G8 VP7 genes between man and cattle might have occurred on more than one occasion, or may be continuing. This may explain why human G8 viruses possess a number of different characteristics, such as diverse P-types and electropherotypes. It is possible that the G8 VP7 genes were introduced into different human viruses during independent transmission events. This may also explain why human G8 strains are geographically more widely dispersed, whereas human G6 viruses display a restricted distribution and, to date, have been found in only two locations, Italy and Australia [10, 17]. Given that the detection of the Italian G6 strains preceded the Australian ones by at least 6 years, it is possible that a PA169-like virus was transmitted to Australia with a human host.

An alternative explanation is that cattle and man are the recipients of the G6 and G8 VP7 genes from another host. Serotype G6 and G8 rotaviruses have a wide distribution in animal species and have been reported in sheep, goats and pigs (G6) and pigs and horses (G8), as well as cattle [18-21]. Liquid hybridisation analysis of whole genomes of human and bovine G8 viruses suggested that this serotype exists as epidemiologically distinct viruses which have arisen from different sources [16]. It was further suggested that the source of these viruses may be a yet unidentified host [16]. Solid-phase hybridisation analysis has indicated that G6 human and bovine viruses differ by the possession of different VP4 genes [17], whereas G8 human and bovine viruses possess different VP4 and NSP1 genes [14]. Given that these genes encode proteins that are involved in host range restriction [22], direct transfer may not have occurred and the possibility of an intermediate host, in which a 
a
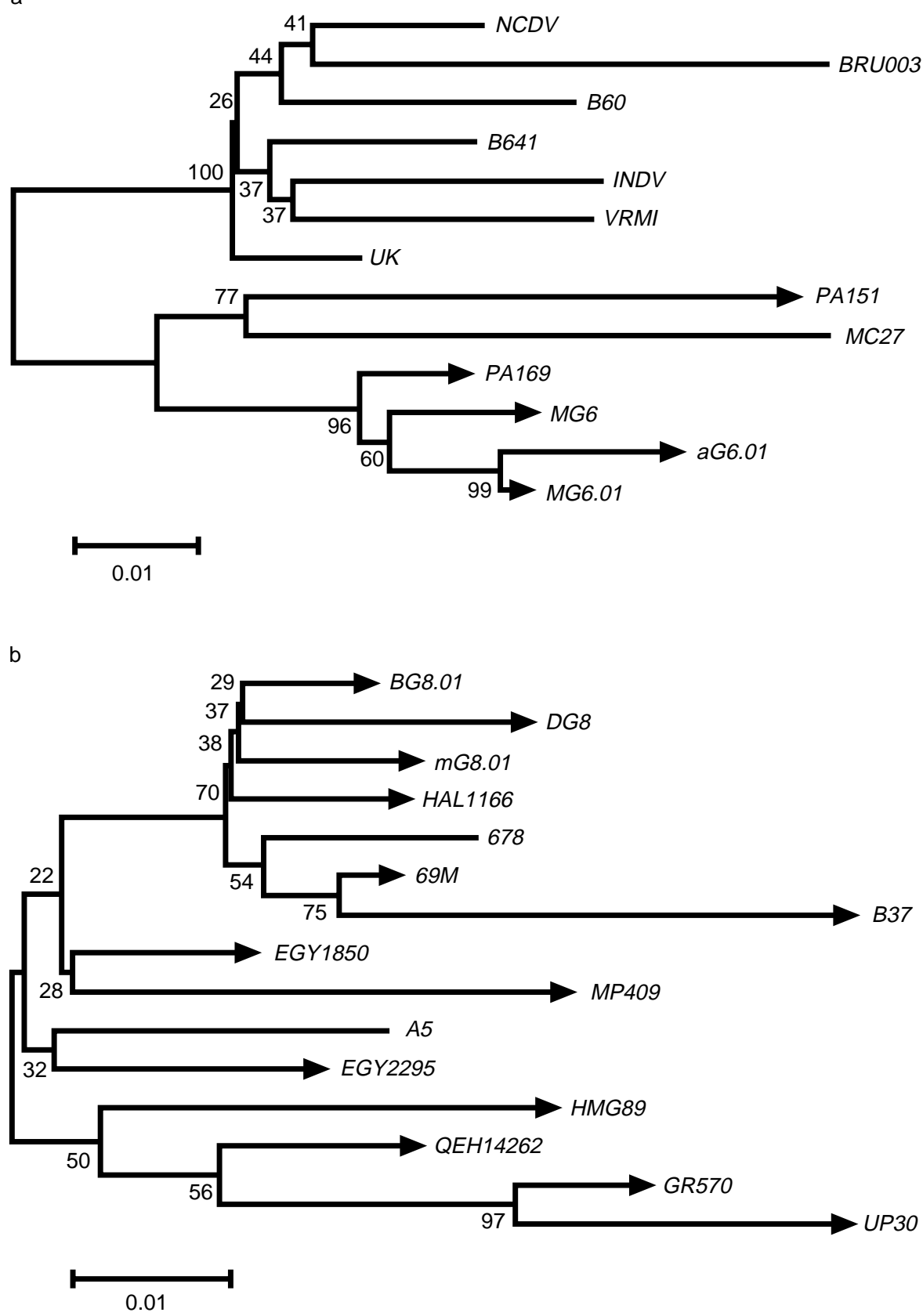

Fig. 2. Unrooted radial phylogenetic trees of VP7 amino acid sequences from bovine and human serotype G6 (a) and G8 (b) rotaviruses. Human sequences are indicated by a closed triangle $(\boldsymbol{)})$. The trees were generated by MEGA analysis using neighbour-joining. Bootstrap values are shown at the branch nodes. The scale bar is proportional to genetic distance. Sources of sequences are as indicated in Fig. 1.

re-assortment event occurred, is plausible. A possible intermediate host for G6 viruses may be domestic cats, as the P-type found in PA151 is also found within this species [13]. Hence, the G6 VP7 may have been transmitted to a PA151-like human virus from cattle through a feline intermediate.

With the increased use of improved typing methods for rotavirus (e.g., specific RT-PCR), it is likely that the detection of rare or emerging serotypes will continue, both in man and animals. The sequences of VP7 proteins from G6 and G8 viruses isolated from species other than man and cattle are currently unavailable. Analysis of these may provide new insights into the process of inter-species transmission of rotaviruses. It may also help to determine the impact that the introduction of novel genes will have on the evolution of the human virus population. Therefore, it will be of particular interest to monitor the epidemiology of human rotaviruses in regions where trials of candidate bovine-based human vaccines will be conducted.

This work was supported by the Royal Children's Hospital Research Institute. We thank Paul Masendycz and Helen Bugg for identifying 
non-typable samples; Ruth Clark for adapting viruses to cell culture; Dr Ian Holmes (University of Melbourne) for monoclonal antibody N2/A7; Michael Witt (Pathology Department, Royal Brisbane Hospital) and Andrew Lawrence (Microbiology Department, Women's and Children's Hospital, Adelaide) for sending faecal specimens.

\section{References}

1. Kapikian AZ, Chanock RM. Rotaviruses. In: Fields BN, Knipe DM, Howley PM et al. (eds) Fields Virology, 3rd ed, vol 2. Philadelphia, Lippincott-Raven. 1996: 1657-1708.

2. Parashar UD, Bresee JS, Gentsch JR, Glass RI. Rotavirus. Emerg Infect Dis 1998; 4: 561-570.

3. Alfieri AA, Leite JPG, Nakagomi O et al. Characterization of human rotavirus genotype P[8]G5 from Brazil by probehybridization and sequence. Arch Virol 1996; 141: 2353-2364.

4. Cunliffe NA, Gondwe JS, Broadhead RL et al. Rotavirus G and $\mathrm{P}$ types in children with acute diarrhea in Blantyre, Malawi, from 1997 to 1998: predominance of novel P[6]G8 strains. J Med Virol 1999; 57: 308-312.

5. Ramachandran M, Das BK, Vij A et al. Unusual diversity of human rotavirus $\mathrm{G}$ and $\mathrm{P}$ genotypes in India. J Clin Microbiol 1996; 34: 436-439.

6. Greenberg H, McAuliffe V, Valdesuso J et al. Serological analysis of the subgroup protein of rotavirus, using monoclonal antibodies. Infect Immun 1983; 39: 91-99.

7. Gouvea V, Allen JR, Glass RI et al. Detection of group B and $\mathrm{C}$ rotaviruses by polymerase chain reaction. J Clin Microbiol 1991; 29: 519-523.

8. Gouvea V, Glass RI, Woods P et al. Polymerase chain reaction amplification and typing of rotavirus nucleic acid from stool specimens. J Clin Microbiol 1990; 28: 276-282.

9. Coulson BS, Unicomb LE, Pitson GE, Bishop RF. Simple and specific enzyme immunoassay using monoclonal antibodies for serotyping human rotaviruses. J Clin Microbiol 1987; 25: 509-515.
10. Palombo EA, Bishop RF. Genetic and antigenic characterization of a serotype G6 human rotavirus isolated in Melbourne, Australia. J Med Virol 1995; 47: 348-354.

11. Kumar S, Tamura K, Nei M. MEGA: Molecular Evolutionary Genetic Analysis, version 1.01. Pennsylvania State University, University Park, PA 16802, USA. 1993.

12. Green KY, Hoshino Y, Ikegami N. Sequence analysis of the gene encoding the serotype-specific glycoprotein (VP7) of two new human rotavirus serotypes. Virology 1989; 168: 429-433.

13. Estes MK. Rotaviruses and their replication. In: Fields $\mathrm{BN}$, Knipe DM, Howley PM et al. (eds) Fields Virology, 3rd ed, vol 2. Philadelphia, Lippincott-Raven. 1996: 1625-1655.

14. Palombo EA, Clark R, Bishop RF. Characterisation of a "European-like" serotype G8 human rotavirus isolated in Australia. J Med Virol 2000; 60: 56-62.

15. Snodgrass DR, Fitzgerald T, Campbell I et al. Rotavirus serotypes 6 and 10 predominate in cattle. J Clin Microbiol 1990; 28: $504-507$.

16. Browning GF, Snodgrass DR, Nakagomi O, Kaga E, Sarasini A, Gerna G. Human and bovine serotype G8 rotaviruses may be derived by reassortment. Arch Virol 1992; 125: 121-128.

17. Gerna G, Sarasini A, Parea $M$ et al. Isolation and characterization of two distinct human rotavirus strains with G6 specificity. J Clin Microbiol 1992; 30: 9-16.

18. Gouvea V, Santos N, Timenetsky M do C. Identification of bovine and porcine rotavirus $\mathrm{G}$ types by PCR. $J$ Clin Microbiol 1994; 32: 1338-1340.

19. Iša $P$, Wood AR, Netherwood $T$, Ciarlet $M$, Imagawa $H$, Snodgrass DR. Survey of equine rotaviruses shows conservation of one $\mathrm{P}$ genotype in background of two $\mathrm{G}$ genotypes. Arch Virol 1996; 141: 1601-1612.

20. Munoz M, Lanza I, Alvarez M, Carmenes P. Prevalence of neutralizing antibodies to 9 rotavirus strains representing 7 Gserotypes in sheep sera. Vet Microbiol 1995; 45: 351-361.

21. Pratelli A, Martella V, Tempesta M, Buonavoglia C. Characterization by polymerase chain reaction of ruminant rotaviruses isolated in Italy. New Microbiol 1999; 22: 105-109.

22. Burke B, Desselberger U. Rotavirus pathogenicity. Virology 1996; 218: 299-305. 